maps and views. Appleby, 1915 (but not dated). Price 18.-This work forms a useful guide to the geological structure of this district, and should be much sought after by tourists interested in the structure of rocks, the Appleby region being one of the best centres for such studies in Great Britain. Dr. Marr's portion of the work is a re-issue of his Geology of the Appleby District, published some years since, which, according to a newspaper paragraph, is now "brought up to date".

9. Catalogue of the Books, Manuscripts, Maps, and Drawings in the British Musedm (Natural Histort). Vol. V : SO-Z. 4to; pp. 1957-2403. London: Dulau \& Co., 1915. Price $£ 1$ per volume.-We have already spoken (GEoL. MAG., 1903, pp. 415-18; 1910 , pp. 475-6) of the merits and value of this Catalogue, and have therefore only to call attention to the completion of the main work. Mr. B. B. Woodward has fortunately catalogued the whole series from $A$ to $Z$, and thus the publication has an uniformity and completeness unusual in so large an undertaking. While congratulating Mr. Woodward and expressing our indebtedness to him for the relief he has afforded to all those who struggle through scientific literature, we hope we shall not be indiscreet in mentioning that a supplementary volume which will include many additions and rarities acquired while the Catalogue has been going through the press (1903-15) has been arranged for. The manuscript for this is already nearly finished and will include the large and valuable library of entomological books and serials handed over by Lord Walsingham to the Museum with his collection of microlepidoptera. And advantage will be taken for the inclusion of bibliographic matter of any importance affecting the main entries, emendations of dates, and other detail for which we look in vain in most catalogues of the kind.

\title{
MISOFIIAINOUS.
}

The Royal Society of Canada, Ottawa.-Mr. J. B. Tyrrell, M.A., M.Inst.M.M., F.R.S. (Canada), F.G.S., Mining Engineer, of Toronto, was elected President of the Geological Section of the Royal Society of Canada at its annual meeting held in Ottawa on May 25-7.

Erratum.-In the August Number, p. 353, footnote ${ }^{1}$ (third line), for "deposited by the Rhine Glacier", read " Rhone Glacier".

THe following lines, indited by a friend after reading Matthew Arnold on Culture, have reached the Editor's box, and may serve to relieve the tedium of the season:-

\section{Culture and Kultur.}

While Culture in Britain induces

Swifter progress to Sweetness and Light,

His Kultur the German seduces

Towards Arrogance, Envy, and Spite.

T. V. H. 